\title{
Public artworks and the freedom of panorama controversy: a case of Wikimedia influence
}

\section{Mélanie Dulong de Rosnay}

Institute for Communication Sciences, French National Centre for Scientific Research (CNRS), Paris, France

\section{Pierre-Carl Langlais}

CELSA, Université Paris Sorbonne, France

Published on 16 Feb 2017 | DOI: 10.14763/2017.1.447

\begin{abstract}
Freedom of panorama, an exception to copyright law, is the legal right, in some countries, to publish pictures of artworks which are in public space. A controversy emerged at the time of the discussions towards the revision of the 2001 European Copyright Directive, opposing free knowledge communities as advocates of the public domain, and authors' collecting societies aiming at preserving their constituents' income. The article decrypts the legal framework and political implications of a topic which has been polarising copyright reform lobbyists, and analyses its development within the public debate since the XIXth century. Articulating legal analysis with text mining, this article aims at contributing to the policy debate.
\end{abstract}

Keywords: Public domain, Public art, Freedom of panorama, Public space, Text-mining, Copyright law, Lobbying

\section{Article information}

Received: 01 Aug 2016 Reviewed: 22 Dec 2016 Published: 16 Feb 2017

Licence: Creative Commons Attribution 3.0 Germany

Competing interests: The author has declared that no competing interests exist that have influenced the text.

URL:

http://policyreview.info/articles/analysis/public-artworks-and-freedom-panorama-controversy-case-wi kimedia-influence

Citation: Dulong de Rosnay, M. \& Langlais, P.-C. (2017). Public artworks and the freedom of panorama controversy: a case of Wikimedia influence. Internet Policy Review, 6(1).

https://doi.org/10.14763/2017.1.447

Disclosure statement: One of the authors is a founding member and former president of the Communia association for the digital public domain. The other author is a member of Wikimedia France. Both associations are advocating in favour of a freedom of panorama exception. 


\section{INTRODUCTION}

Freedom of panorama is the legal right in some countries to publish pictures of artworks, sculptures, paintings, buildings or monuments that are in public spaces, even when they are still under copyright (Brazil, Germany, UK, US). However, in some other countries (Argentina, Belgium, France, Greece, Italy), this public space is "blacked-out" (see Figure 1) as illustrated in a campaign to denounce restrictions on the public domain, which is literally masking buildings on photographs.

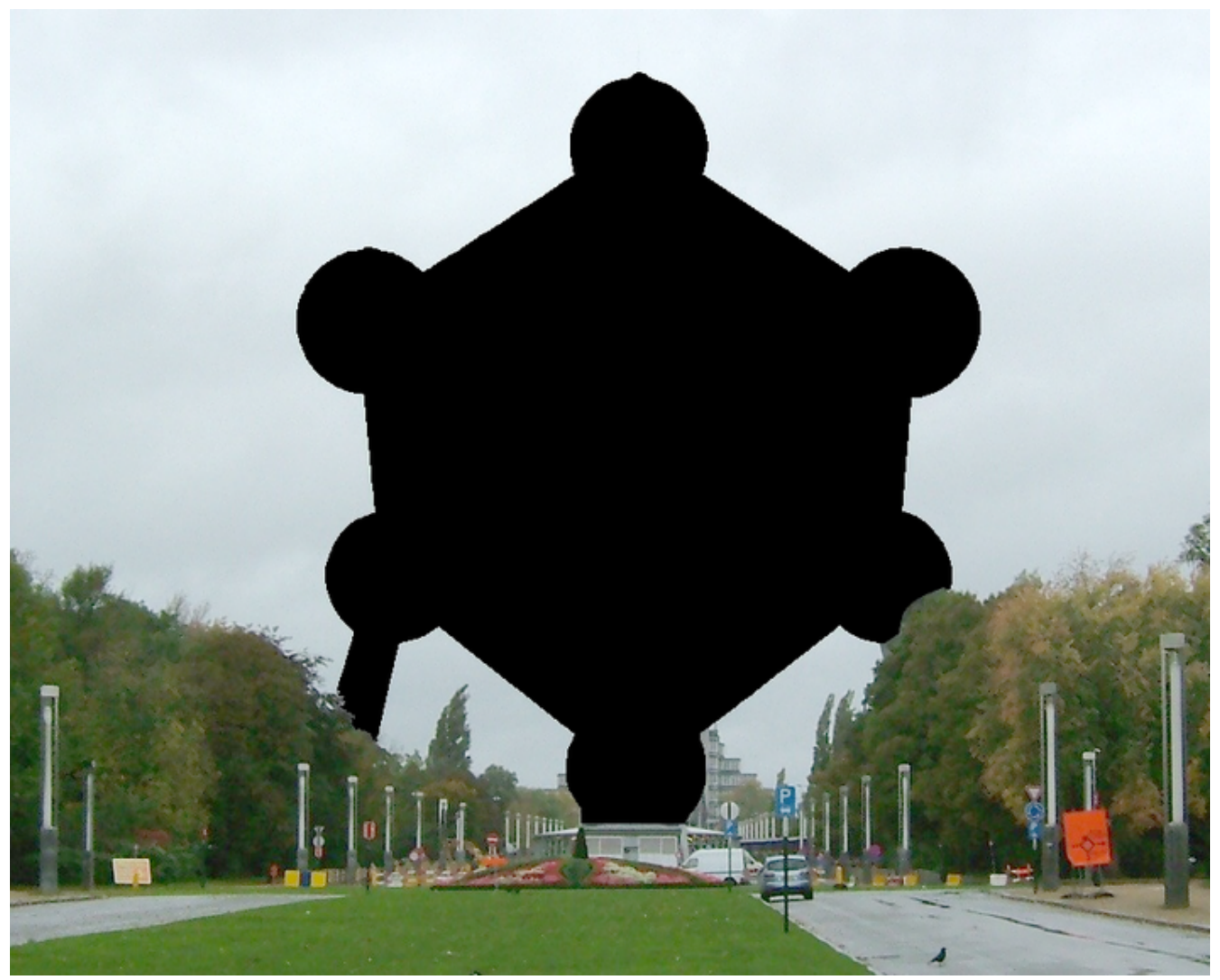

Figure 1: A "blacked-out" reproduction of the Atomium of Brussels1

Authors of works which are in the public space can, in countries where usage of these works is covered by copyright, effectively hide otherwise unprotected landscape. Users who take a selfie in front of the Pyramide du Louvre in Paris would not be authorised to post it on social media Wikipedia, the poster case and most vocal advocate of a freedom of panorama in Europe, claims it would not be able to play its role of memory institution to provide high-resolution pictures of works of art which are "on" the public domain if they are not "in" the public domain. In that sense, Wikipedia is introducing a semantic confusion between the public space and the public domain in the sense of copyright, claiming that public space works should not be covered by copyright. Public domain, the status after the expiration of copyright, signifies that a work can be freely reused, without having to ask for permission or pay a remuneration. The legal research to be performed by photographers requires determining the date of death of the author, here the architect or outdoor artist, adding 70 years, and taking into account tremendous variations (Angelopoulos, 2012). Such a duty of care can be all the more difficult as the authorship of such a thing as a building or an outdoor monument is not documented next to the work, such as in a museum. 
Beyond guidelines for photographers or more generic studies on public art, there is very little legal literature in English on the topic of freedom of panorama. The literature 2 review gathers only two peer reviewed articles (Newell, 2011; Bertoni \& Montagnani, 2015), one invited article in a law journal by the proponent Member of European Parliament (MEP) (Lorrain \& Reda, 2015), a report issued by a clinic (Lobert \& al., 2015) and a brief published by an advocacy organisation (Nobre, 2016). More importantly, there is no impact study on the effect of the existence of such an exception and without data, policy debate is difficult.

This article analyses the controversies around freedom of panorama as an exception to copyright. We analyse the emergence of the concept in history (1), its treatment in different legislations and in recent case law (2), the state of the current policy controversy among the main stakeholders (3) and the media debate (4).

The analysis will focus on selected countries because of their representativity on both sides of the debate: Germany as the birthplace of the exception, Belgium as the latest jurisdiction to have adopted an exception during the current controversy; France and Italy as countries granting rights to works even if in the public domain; Sweden as another country with a recent case law against the exception. A few examples of UK law, a common law jurisdiction, have been included when remarkable.

This research intends as such to contribute to the discussions at the European and the member state's level on whether to harmonise freedom of panorama, to maintain the current practices of collective management societies which collect rights for the use of cultural works located in the public space, or to implement intermediary measures, for instance to authorise only noncommercial freedom of panorama.

As a part of the ongoing revision of the European Union Directive on Copyright in the Information Society, the topic has been antagonising lobbyists as a polarising example of the extension of users' rights online, leading in parallel to different implementations in France and Belgium in June 2016, and to not being included in the current revised Directive proposal. According to the European branch of the American political journalism organisation Politico, the debate "says a lot about the national, ideological and even generational divisions within Europe over how to regulate the digital future. And it underscores the power of one country, France, to impose its will on the rest of the European club" 3 .

The analysis of the media and the lobbying campaign reveal that the main actors of the debate are collecting societies, whose revenues would be affected should the exception become compulsory, or larger. The users' side, the analysis finds, is mainly represented by Wikipedia, an organisation at the forefront of the campaign and therefore also of this paper. While other stakeholders of the online space are affected by this legal prerogative, neither social media platforms, nor the press, chose to join the campaign towards a new or broader exception.

\section{THE ORIGINS OF THE CONCEPT OF FREEDOM OF PANORAMA}

The lack of harmonisation within Europe is the result of a complicated and varied history within the member states. The representability of the public sphere has been significantly, if not mostly, defined through jurisprudence and involves a wide array of concurring rights and cultural norms. Copyright protection is only a piece of this puzzle, albeit the leading one in the 
latest debates.

In this section, we provide some background on the notion of public artworks and present the historical foundations of their copyright status in Europe. While the concept has a long and complicated history following intense European debates on author rights and different cultural foundations for copyright in the 1830 , the exact concept of "freedom of panorama" does not apparently appear before the end of the XXth century 4 .

\subsection{REGULATING PANORAMA REPRESENTATIONS IN THE "AGE OF MECHANICAL REPRODUCTION"}

Freedom of panorama is closely related to the history of communication technology. The concept first emerged in the 1840 s in a context not too dissimilar to that of the current European debate. The legal aspects and implications of representing the public space was deeply redefined by a wave of disruptive innovations. To paraphrase Walter Benjamin, the work of arts came to the "age of mechanical reproduction": new techniques, such as photography, industrial presses or lithography lifted significant restraints to replications 5 .

The impact of this structural transformation to the regulation of public space reproductions largely exceeds the field of intellectual property.

In France, protection of privacy has long been the leading factor. A coherent sequence of case law effectively banned photographers from most of the urban public sphere by the second part of the XIXth century: the reproduction of streets were assimilated to a breach of privacy (Tissot, 2013). This early debate on freedom of panorama was therefore mainly focused on other issues than intellectual property: most of the (rare) jurisprudence focused on sculpture and other forms of outdoor visual art 6 . Given the representativity of the public space was already severely limited on other grounds, there wasn't much incentive to settle the theoretical patrimonial rights of the architects.

In Italy, protection of the cultural heritage rather than copyright may have been the initial incentive. As soon as the early XVIIIth century, the Papal States and the Kingdom of Naples had prohibited the reproduction (through engraving or other means) of archeological remains, which were frequently displayed in the public space 7 : the current Italian law on Cultural Heritage, which only allows non-commercial reproduction of "cultural heritage goods" (Morandi, 2011) probably draws from such ancient provisions.

\subsection{CENTERING THE REGULATIONS ON COPYRIGHT: A GERMAN INNOVATION}

In Germany the debate took another turn that brought it much closer to the terms of the current debate: it came to produce the very first piece of legislation establishing a copyright exception for works of arts displayed in the public sphere. German law was at the time a complex byproduct of confederate agreements and, still, widely autonomous small states. In 1837, the German Confederation approved a new author right disposition against reproductions ("gegen den Nachdruck"). As was the use at the time, it made a special case of mechanical reproduction ("auf mechanischem Wege") 8. The reform aimed to establish a common standard on copyright law within the Confederation (with a minimal protection length of 10 years) 9.

Several members of the German Confederation quickly attempted to soften some aspects of this stricter legal frameworks - a process somewhat analogous to the subsidiarity principle in the contemporary EU. Three years later, in 1840, the Kingdom of Bavaria edicted the very first "freedom of panorama": an exception to this general rule regarding the "work of arts and 
architecture in their exterior contours" situated in a public space (quoted in Chirco, 2013). The initiative was imitated in other states so that the ongoing unification process of Germany opened up a nationwide debate on the proper imbalance between artists' right to control the dissemination of their work and the preservation of the public sphere as a "common good" ("Gemeingut"). The debate also served to overcome the different definitions of the public and private spheres within the German states. In 1876, the German parliament agreed on a general exception in similar terms to the original Bavaria initiative.

\subsection{AT THE CROSSROAD OF DIFFERENT RIGHTS}

Even in Germany, intellectual property wasn't the sole concern but rather the main legal construct on which additional rights and concerns could be subsequently transplanted. Reproduction from private place were excluded from the scope of the exception. While this may make little sense from the perspective of a copyright exception, this has definitely served to ensure the protection of the "individual sphere" (Individualsphäre). Jurisprudence has consistently excluded photographies taken from private places or helicopters as they allow to depict the building beyond what could "be seen from the public road" 10 . More recently, Google Street View has been the focus of extended trials in Germany on account of the use of techniques ("a six-foot-tall hedge") that exceeded the normal viewpoints of a street on private place (Geissler, 2012, p. 919).

While it has resulted in a complex construct involving several rights, the institutionalisation of freedom of panorama in Germany remains exceptional. The United Kingdom has long applied a similar provision, but mainly through jurisprudence. Reproductions of architectural works in two dimensions were authorised on the account of "the risk to which a citizen would be exposed who was photographing or sketching in any urban neighbourhood" (Gibbs-Smith, 1970). This principle has only been institutionalised in 1988 (as the Section 62 of the Copyright, Designs and Patents Act).

Significantly, even in Germany there was no acknowledged and uniform name to designate this array of exceptions and restrictions. While the concept was 170-years old, the word only emerged in the 1990s. "Panoramafreiheit" was likely of Swiss origin 11. This vernacular expression quickly disseminated in German and French-speaking countries 12. This early success can be attributed to an appropriate semantic turn in the burgeoning debate on the application of intellectual property on the web: taking the viewpoint of the user. The notion of "exceptions" is mostly relevant to the rightholders by pointing out restrictions to a general framework of protection. The word "freedom" stresses the ability to reuse (or not) an intellectual work. Consequently, the term is very early attested in prospective works on IT law and digital practices 13.

\section{THE LEGAL FRAMEWORK OF FREEDOM OF PANORAMA}

In this section, we introduce the context of public art and the variety of legal options available to regulate panorama (2.1). We then analyse the scope of the exception of panorama in Europe and in selected relevant member states (2.2). In particular, we analyse the question of commercial use interaction with Creative Commons licensing (2.3). 


\subsection{THE BROADER REGULATION OF PUBLIC ART AND CULTURAL HERITAGE}

The broader category of public art is used to inform the question of freedom of panorama, including outdoor works of art and buildings which are still copyrighted, as well as cultural heritage sites, whose reproduction is regulated in some countries (e.g. Italy), even if they are under copyright in the public domain.

Bertoni \& Montagnani (2015) suggest that 'public art' works may express the identity of a community, a state, a nation; they can embody cultural, economic, social, environmental interests, and have civic, commercial, and touristic value. As such, they are more than just simple works under copyright. Public funding is almost always present for the creation or the preservation of public art, giving an argument in favour of the rights of the public to its urban space, at the crossing between intangible copyright (impacting on urban shaping, see Popova, 2012) and the materiality of physical commons.

Parallels and precedents, a useful methodology for lawyers, have been identified by Newell (2011) in cultural heritage law. Italy enforces a charging policy for the reproduction of antique public domain works, Egypt had a similar bill for the pyramids, while Sydney Opera House is relying on trademark law to reach a similar effect.

Other interests identified by Newell are the church authority (they opposed the use of Landowski Christ in Rio in a Hollywood movie) and national security law. French intelligence also tried to remove information on a building considered as classified information.

Finally, another area of law which has been used to control the use of public artworks outside of the narrow and recent scope of the exception of panorama is the incidental inclusion of a work in another work. For example, current case law in France has been relying on another copyright exception of the Directive, article 5.3 (i) which authorises the incidental inclusion of a work or other subject-matter in other material. The legal battle opposing Buren and Drevet to postcards makers in the city of Lyon 14 granted the right of accessory representation of a copyrighted work when it cannot be extracted from a public domain space, namely a contemporary art installation on a public square. Authors can still enjoy other aspects of copyright, notably moral rights, as they sued the municipality to preserve and repair their public artwork.

\subsection{THE SCOPE OF WORKS COVERED BY FREEDOM OF PANORAMA: A LACK OF HARMONISATION}

Freedom of panorama is an exception under copyright, in the countries where it exists, it provides users the legal right under copyright to publish pictures of artworks which are in the public space, without asking for the permission of rightholders or paying royalties.

With some variations, there is no exclusive right for rightholders to control the reproduction of their works, which are in the public domain in countries such as Brazil, Germany, Portugal, the United Kingdom, the United States (Nobre, 2016), the Netherlands, etc... However, some exclusive rights are maintained in Albania, Argentina, Belgium, Bulgaria, France, Greece, Italy, etc. The international review of legislations, conveniently led by Wikipedians, stakeholders of the controversy, reveals a lack of harmonisation in Europe, as well as worldwide ${ }_{15}$, and the existence of broad variations in the scope of the artworks included and the definition of the right.

Given the very late attempt at formalisation presented in section 1, the legal standard provided in the European Directive on Copyright 16 does not define a "Freedom of panorama". It quite 
loosely refers to a panorama exception which may be implemented by member states: the "Use of works, such as works of architecture or sculpture, made to be located permanently in public places".

Artworks can include permanently placed sculptures and $3 \mathrm{D}$ art, be restricted to $2 \mathrm{D}$ art, be limited to buildings only, or include public interiors.

Some jurisdictions have fine grained nuances to be taken into account to assess whether a reproduction can fall under a national exception. For instance, UK law 17 is distinguishing among 2D "works of artistic craftsmanship" and 2D "graphic works" for which exclusive rights stay reserved. This could be due to the intervention of a category of authors, even if we have not found the source of this difference.

Another example of national nuance is German law, which allows photographers to take pictures that are visible from publicly accessible places. According to case law, which has been influenced by a strong conception of privacy as underlined in the previous section, this includes private ways and parks with common access. However, it does not include railway station buildings or platforms. The picture must be taken from a publicly accessible point. As we have seen in the previous section, it is not permitted to take a picture of such a building from a private house or from a helicopter, which do not qualify as public spaces.

\subsection{THE QUESTION OF COMMERCIAL USE: AN IMPOSSIBLE COMPROMISE}

The scope of the right of panorama may be restricted to non-commercial use or include even commercial usages. In this section, we present the solutions which have been adopted in 2016 in French and Belgian law as well as in Swedish case law. Belgium introduced an exception covering also commercial usages, while France and Sweden continue to exclude them. We will explain the reason why the controversy has been crystallising around this notion: Wikipedia, the main actor lobbying for an exception also covering commercial rights, uses a Creative Commons license which also authorises further commercial reuse.

The dual-track strategy, when lobbyists pursue similar strategies at the national and the supranational levels, has been applied in 2016 by two member states, France and Belgium. They did not wait for the Copyright Directive current revision (discussed in section 3 ) in order to legislate on the question. They ended up with opposite solutions. According to Commissioner Günther Oettinger, "25 or 26 EU nations were ready to introduce freedom of panorama, with France being the only heavy-hitter fighting back" 18 .

Belgium voted an exception on 27 June 2016, creating a freedom of panorama following the limits of the three step test. 19 The French exception 20 voted at the same time excludes commercial uses, without however defining what constitute a commercial use (Manara, 2016, Rosati ${ }_{21}$ ). At the same time, the topic of public artworks which are in the public domain was also addressed in another law regarding national heritage. Following Jean-Marie Cavada's French MEP amendment to the Reda report, France introduced on 29 June 2016 a discretionary right for the commercial use of public domain buildings. Based on the right of image of national domain, article L. 621.42 of the law 22 foresees that

The use for commercial purposes in all media of the image of the buildings that make up the national domains, is subject to prior authorisation from the manager of the relevant part of the national domain (...) (except) when the image is used in connection with the exercise of public tasks or for cultural, artistic, educational, 
teaching, research, information and news illustration. 23

As explained in the introduction, Wikipedia is the only actor of the controversy affected by the distinction between commercial uses and non-commercial uses and moreover, carefully excluded of this limitative list of non-commercial uses which are free. It is the only major actor in the controversy committed a Creative Commons license, unlike Facebook or Twitter, who have not been vocal in the debate. In that sense, Wikipedia's activities are here assimilated to a social media platform, on which users are posting images whose copyright could easily be cleared for a fee. Wikipedia would only be better protected if the association's mission was assimilated to a public service, given the patrimonial missions fulfilled by the encyclopedia.

The consequence of restricting freedom of panorama to non commercial uses arises from the license which is used by Wikipedia and its viral effect. The Creative Commons Attribution Share Alike license allows indeed any third party to reuse texts and photos made available on the encyclopedia, even for commercial use. The core of the controversy 24 on commercial use targets usage of public artworks in advertising by commercial brands 25 . Wikipedia is licensed under a Creative Commons licence authorising commercial reuse, in order to facilitate reuse without further question, since the notion of commercial use is difficult to assess. The virality of possible commercial reuse of a picture posted on Wikipedia by a company is the poster case of the argumentation by collecting societies. Such a scenario where the reproduction of an image on Wikipedia would be reused by a commercial advertising campaign could happen in theory if photographs are available for free reuse on Wikipedia under the Creative Commons license. In practise, professional commercial re-users should know that the license does not apply to them when national heritage law decides otherwise.

From 2005 to 2015, the conflictual relationship between Wikimedian communities and collecting societies has been revolving around this question. Collecting societies proposed a free license to Wikimedia chapters in countries which do not have the necessary exception for Wikipedians to post reproductions: Sweden and France. The contracts were proposing a compromise license to publish low resolution photos under a Creative Commons Attribution Non Commercial No Derivatives license (BY NC ND) in order to prevent further reuse by commercial companies and modifications allowed by the standard licenses used on Wikimedia projects. Both the associations behind Wikimedia Sweden and Wikimedia France rejected the proposition, which would not grant the right to redistribute high-quality works under the licenses accepted by the Wikipedia policy, promoting the largest dissemination of free knowledge, including reuse for commercial purposes. A French rightholders' representative 26 was puzzled that the hierarchy of norms would be reverted, and international treaties such as the Berne Convention granting exclusive rights to authors should not be submitted to a private contract. In the case of Sweden, negotiations took place during a lawsuit opposing the Swedish Collecting Society $v$ Wikimedia in Sweden 27 on the use of an image whose rights are managed by the collecting society. The Court followed article 24(1) of the Swedish Copyright Act: "Works of fine art may be reproduced in pictorial form 1 . If they are permanently located outdoors on, or at, a public place" (...)"

In direct application of the Berne Convention's three step test, a standard in copyright, the judge made no exception for an online publicly accessible database, the commercial objective or absence thereof was irrelevant in the exception. The discussion opposed arguments in favour of an exception to copyright: the public interest to reproduce freely outdoors or public spaces, the fact that analogue dissemination is not prejudicial, but online dissemination was assessed as 
prejudicial to rightholders' legitimate interests as it could deprive them of potential commercial revenue. The collecting society BUS meanwhile recalled that Wikimedia had refused to sign a licensing agreement that "would have cost several thousand kronor per year" (several hundred euros/dollars) and had instead "chosen to spend hundreds of thousands of kronor on lawyers' fees." " This argument offers a transition to the next section, which after a presentation of the legal argumentation, analyses statements which may be more political than based on law.

\section{THE POLICY DEBATE}

This section presents the policy arguments behind statements used by policymakers and lobbyists. The position on commercial reuse rights which was just described in the previous section is more a matter of principle for Wikipedia than a financial consideration. A Trojan horse, freedom of panorama is also emblematic of the battle of users' rights against copyright extension. The reaction of the Belgian collective society director after the vote of the exception also covering commercial rights summarises it well as a possible first step to get more exceptions in other fields of copyright:

\section{One suspects the online encyclopedia to want maximum freedom online. This is only a skirmish. The next step will be to get the right of reproduction of music and then films. You will see: by now pressing the freedom of panorama, they will want more $\mathbf{2 8}$.}

Nevertheless, the interest may appear disproportionate, developing a media hype with little substance, as policy arguments are not very elaborate. Leaflets developed by both sides are mostly debunking the other side's arguments as counter-truths (Wikipedia, ADAGP).

\subsection{THE CONTEXT OF A PRO-USERS' RIGHTS FREE CULTURE COALITION}

While revealing the discrepancies among member states' legislations and general approach towards copyright, the freedom of panorama has been framed as a European issue within a European public sphere. Public awareness on copyright and users' rights in general have already been raised by protests related to international treaties (SOPA, PIPA, ACTA), but the discussions surrounding the Reda Report in June 2015 have initiated a wave of continuous media coverage on an otherwise little known issue. Transnational epistemic communities such as the Wikimedia projects played an instrumental role in shaping and disseminating advocacy discourses in favour of freedom of panorama within the EU and gained prominence on the Brussels lobbying scene. Consequently, rightholders and copyright collectives have partly joined to oppose these views across national boundaries 29.

What is really at stake is the changing landscape of professional, industry and social coalitions regarding regulatory models on intellectual creation. As Bullich (2011) underscored, the long time evolution of intellectual property law can be partly explained by ever-evolving coalitions between industries, artists, amateurs and consumers, and by their ability to define strong enough consensus to push forward effective legal reforms. Since the last European copyright reform in 2001, the existing state of coalitions has deeply changed through the emergence of new actors, such as social media and user generated content commercial platforms and selfregulated commons based peer production communities.

As a proxy, freedom of panorama appears as an effective testbed to measure the "strength" of 
each coalition before focusing on more radical and structural issues. It will be interesting to see if free culture communities (Wikipedia, Creative Commons and public domain advocates) really develop opportunistic alliances. A longtime argument of collecting societies 30 is to suggest the existence of an alliance with major commercial platforms such a Google, which benefits from a looser copyright reform, as conveniently also advocated by these non-profits on their behalf. Indeed, Google, through Google Street View, Google Trips or Niantic for Pokemon Go, benefit commercially from the reproduction of the entire public space, which includes copyrighted artworks and buildings for which collecting societies could charge rights for artists.

\subsection{HOW WIKIMEDIANS SHAPED A EUROPEAN CONCERN AROUND LEGAL UNCERTAINTY}

In the meanwhile, the long term argument in favour of freedom of panorama is legal certainty for users of social media platforms and Wikimedians posting pictures of public artworks to illustrate articles. The need to define a coherent international policy in very large contributive projects, mostly composed by non-lawyers developing an interest for copyright as it affects their online activities, implies to clarify the "grey area" within copyright law: the Wikimedia projects and similar commons-based initiatives (such as the Open Knowledge Foundation with The Public Domain Review or, in France, the collective Savoirscom1) have lead extensive collaborative work on even very obscure legal matters, for instance in order to safely evaluate the entry of a work in the public domain and assess its free reusability.

Wikimedian communities played an instrumental part in reshaping the debate from the users' perspective and supporting the most adequate expression to this outlook ("Freedom" rather than "exception") to reverse the rhetoric from a permission into a positive right. No stakeholder has taken a more vocal and influential call in favour of a European freedom of panorama, which materialised through the display of a banner seen by millions of Europeans.

Two factors seem to have contributed to such a high degree of involvement:

1. Wikimedian-projects are community-run. While the Wikimedia Foundation is liable for the content displayed, it has almost no authority on the internal policy-making of local projects. Consequently, contractual settlements usually reached by collecting societies and web companies would be very hard to negotiate with a self-governing distributed community.

2. Wikimedian-projects are transnational. The Wikipedia projects are structured around linguistic communities and may have to comply with differing legislations (for instance, German, Swiss and Austrian law may all be relevant on the German-speaking Wikipedia). Therefore, any further harmonisation within the European member states can relieve significantly the heavy legal checking process led by volunteers.

In 2004-2005, Wikipedia reached a mainstream audience: articles appeared, for the first time, in the spotlight of Google search results, sometimes topping institutional websites. Rightholders took notice of this emerging actor and initiated extensive check of its compliance to copyright. Institutions representing rightholders and copyright collecting societies contacted Wikipedian users in order to clarify the situation of representations of "protected buildings" that should give way to proper remuneration.

While the community mostly deleted the targeted images, the extended qualification given to copyright protection of public artworks got overstretched to "copyfraud" (Mazzone, 2006), the claiming of additional rights on public domain work beyond copyright. For instance, the database of the French Ministry of Culture systematically added copyright mentions (such as "C) CMN") to historical monuments. The willingness to comply with existing law quickly gives way 
to frustrating feelings on the uncertainty of users rights. French Wikipedians unfavourably compared their situation to their German and English counterparts. In April 2005, an issue of Wikimedia Quarto recalled a wave of takedown notices from cultural institutions to the French community. The cases led either to the deletion of the images by Wikimedians or were dropped by the claimants, reinforcing the frustrated feelings on behalf of the community and prompting a call for the legalisation of freedom of panorama in France. By 2005, there were no real political opportunities to promote such a change. Fundamental debates on the evolution of author rights were unlikely to occur again for several years.

\subsection{THE IMPOSSIBILITY TO LEAD AN ECONOMIC ASSESSMENT ON REVENUES IMPACT}

After users' concerns about legal uncertainty, this section describes another area where the argumentation is more political than evidence-based. Authors' societies claim the right of panorama is a major part of artists revenues. Nevertheless, this claim could not be confirmed by the authors because of the personal information contained in the royalties database, mixing for each artist rights on artworks located in the public space and artworks not located in the public space, making it difficult to separate revenues which would be affected by an exception and assess the possible loss.

French collective society claims ${ }_{31}$ to extract an important part of graphic and plastic artists' royalties from commercial uses of public artworks in advertising campaigns. They also propose to grant free or cheap licenses for educational or press usages, a deal which was not accepted by Wikimedia France or Sweden mainly because of its limitation to non commercial usages. Figures on revenues directly related to the absence of an exception of panorama have been disclosed by the ADAGP ${ }_{32}$ (Association pour la Diffusion des Arts Graphiques et Plastiques), the French collecting society for graphic and plastic artists' authors rights, collecting royalties for the use of artworks, including those located in public spaces. These could not be verified by independent sources. The figures claim that public art represents significantly more than half of the total advertising revenues distributed to its members (58.2\% on the $2000-2015$ period).

A comparison of data from countries which have freedom of panorama, with revenues in countries which do not have such a right, could contribute to identify the economic impact of the exception. Basic financial data is available in public reports, as collective management organisations are in charge of a mission of public service. The cross-checking of such information with broader data on the economics of copyright could help to evaluate the impact of the absence of freedom of panorama on the global amount of rights distributed to authors, designers and architects of outdoor works.

Access to figures on revenues impact would require to analyse collecting societies databases. With the additional issues of personal data, and of reciprocal trust in the absence of independent source, royalties are associated to artists, and data mining would require a knowledge of which of their works is placed in the public space. And even if figures were available, it is not certain that the comparison among countries would allow to draw conclusions. According to the Architect Council of Europe's public figures ${ }_{33}$, architects revenues are generally higher in countries which benefit from a freedom of panorama, but these countries generally have a higher standard of living (e.g. salaries are higher in the UK than in Greece), and would require a weighted quantitative analysis according to GDP per capita.

The core point of conflict is commercial usage. In some cases, the usage does not even depend on copyright. For example, a license agreement is required to build a house from architectural 
drawing. And its reproduction can appear on different media, all presenting substantial differences as for the possible impact for the author: photographies on a social media platform or in an advertising campaign, news reporting, art book, educational material, T-shirts. The balance between the possible depreciation of the value due to the reproduction and the enjoyment of the public is hard to obtain (Bertoni, Montagnani, 2015).

In any case, the economic, social and cultural impact of freedom of panorama triggers freedom of digital services, user generated content and freedom of expression, art and design education and publishing. The discussion is thus much broader than what a quantitative assessment of the impact on rightholders revenues would reveal. As it has already been demonstrated in a previous controversy in the field of copyright, the legalisation of peer-to-peer filesharing,

"Disputes focused principally on revenue impacts neglect the fact that the online
world is changing. Revenue streams are proxies, and inadequate ones at best, for the
massive changes in the online sharing culture that lets citizens and consumers enjoy
many new opportunities for creative production, a growing number of which are
inconsistent with the balance established by current legislation between their
interests and those of the creative industries" (Cammaerts, Mansell, Meng, 2013).

\subsection{THE ARGUMENTS IN THE POLICY CONTROVERSY AT THE EUROPEAN PARLIAMENT}

The controversy between public domain advocates (3.1) asking for legal security and denouncing copyfraud (3.2) and authors' societies asking to preserve a revenue stream in countries where it still exists (3.3) emerged in the media and in the European Parliament when discussions on the revision of the Copyright Directive proposed to include an exception of panorama. A draft report 34 released on 15 January 2015 by Rapporteur MEP Julia Reda, in its recommendation 16, "Calls on the EU legislator to ensure that the use of photographs, video footage or other images of works which are permanently located in public places is permitted".

This proposition raised opposition and amendments from copyright holders representatives which will be presented in this section. The framing of the debate is two-sided and opposes copyright maximalists (or extremists according to another rhetoric) - who wish to extend the reach of copyright - and minimalists - who seek the expansion of publicly available data which can be freely reused by default.

On the one hand, advocates of the public domain and copyright reform towards more rights for users have instrumentalised the notion of public domain and introduced a confusion between the physical public domain (artworks in public space) and the public domain in the sense of copyright (when copyright expired). This distinction is an important semantic switch which was abused by lobbyists when comparing freedom of panorama and copyfraud.

According to Mazzone (2011) copyfraud is an overreaching copyright claim interfering with legitimate use, an enclosure of the public domain, "one of the anomalies of current copyright". Open access lobbyists including Wikipedians advocate for a positive definition of the public domain (Dusollier \& Benabou, 2007; Dusollier, 2011), the default state of information before the apparition of law ("The Public Domain is the rule, copyright protection is the exception", says Communia Public Domain Manifesto), but this alternative interpretation is not widespread.

Wikipedians therefore interpret a restriction on artworks which are "on" public domain, but not 
"in" the public domain, as copyfraud, introducing a confusion on the scope of copyright on public artworks.

Similarly to the availability of public domain works and open data, freedom of panorama is expected to support innovation and the development of apps, augmented maps, ensuring the promotion of territories and tourism. Cross border discrepancies within the digital single market are presented as a source of legal insecurity and a potential chilling effect for citizens and tourists (Lorrain \& Reda, 2015; Lobert \& al., 2015). They are not compatible with Wikimedia Commons role of memory institution, requiring the end-user to grant a license to commercially use the uploaded photos. Finally, it is likely to discriminate small entrepreneurs who are less likely than bigger industry players to negotiate and pay a licensing fee for the usage of the reproduction of a work of public art.

On the other hand, rightholders representatives and the copyright industry denounce the predation of artists by large corporations. French collecting societies explain that granting an exception would lead to financial loss for artists, no financial impact for Wikipedians, and huge profits for commercial entities which could reuse images found on Wikipedia for free if available there under a license authorising further commercial reuse and modification.

Therefore, collecting societies suggested Wikimedia could use a different, more strict license just for public space artworks, effectively preventing commercial reuse and modification. This would be contrary to the mission of Wikipedia, which aims at diffusing only free knowledge and culture with Attribution and ShareAlike as the only acceptable restriction to the public domain.

Member of European Parliament Jean-Marie Cavada wrote an amendment to MEP Julia Reda's report addressing this notion of commercial use. Voted in June 2015, it stated that:

\section{"The commercial use of photographs, video footage or other images of works which are permanently located in physical public places should always be subject to prior authorisation from the authors or any proxy acting for them".}

Not only neutralising the initial proposed exception, this amendment would have far-reaching consequences: it would remove users' rights which were unaffected under current law, both by importing a restriction in member states which have an exception, and by expanding control to public domain works.

A petition ${ }_{35}$ in favour of freedom of panorama gathered 555,000 signatures and the amendment was rejected. The resolution on the Reda report ${ }_{36}$ voted in July 2015 calls on the Commission "to effectively safeguard public domain works (and) to strengthen exceptions for institutions of public interest, such as libraries, museums and archives, in order to promote wide-ranging access to cultural heritage, including through online platforms".

Both points provided a basis towards an exception, as we argue that Wikimedia Commons fulfils a mission of public interest in the field of digital heritage. However, freedom of panorama did not end in the list of compulsory exception in the proposal of revision of the Directive issued on 14 September 2016 37. It was not proven that the absence of an exception would create a particular risk for harmonisation. In spite of the results of the public consultation conducted during the summer of 2016, which was widely favourable to the introduction of an EU FoP exception, it was decided to ignore the public 'call'. 
Nevertheless, the topic is likely to come back during the Parliament debate. A report of Marc Joulaud for the Committee of Culture and Education published on 6 February 2016 calls the member states to "provide an exception authorising at least the reproduction, use and dissemination, for non-commercial use, of works permanently located in public places" (Amendment 11) $)_{3}$

\section{THE MEDIA REPRESENTATION: HOW THE MEDIA DISCOVERED "FREEDOM OF PANORAMA"}

The discussions at the European and national legislative and advocacy level are only one part of a wider conversation within the European public spheres which we present in the final section of this paper. While we haven't been able to locate any use of the expression "freedom of panorama" in the news before 2011 (or, for that matter, of its French counterpart, "liberté de panorama"), hundreds of articles have been devoted to the issue since 2015 in all of the main languages of the European Union. So far, no other envisioned exception in the EU copyright plans has been the focus of such sustained media interest.

To get a clearer outlook on this unprecedented coverage, we have extracted 115 articles from Google News (of which 53 are in English) and 136 articles in French from Europresse, a proprietary database accessible through university credentials 39. While the selection from Europresse is rather stable and comprehensive, the extraction from a Google News query raises significant methodological issues summed up in our supplementary data paper (chiefly, Google News tends to be overinclusive; older results seem to "disappear").

Before delving into statistical analysis, one simple quantitative element stands out: there isn't a single article clearly in favour of copyright protection of publicly displayed art 40 . The shades of commitment are either neutral or pro-freedom of panorama. This unequal stance can be attributed to different strategies. Wikimedian communities strived to make freedom of panorama a standalone issue, whereas copyright collectives rather relied on a general defence of copyright status quo (4.1).

As shown in the previous sections, France is a major and influential stakeholder of the policy debate. The parallel evolutions of French law (that led to a limited exception for noncommercial use and an extension of pre-existing protection to patrimonial buildings in the public domain) partly set the agenda for the European directive. Stylometric analysis of our French corpus reveals a major involvement of Wikimedian communities and organisations in shaping the media discourses on "liberté de panorama" (4.2).

We haven't been able to identify a comparable influence in the English corpus. While Wikimedians made early vocal calls against an harmonised EU non-commercial exception, this involvement was partly covered by competing groups, that used the freedom of panorama controversy to serve their own specific agenda (4.3).

\subsection{BANNERS AND OP-EDS: A CASE OF WIKIMEDIAN INFLUENCE}

In the first part, we showed that the expression "freedom of panorama" did not exist in scholarly publications before the 1990s. Its dissemination in the media is much more recent: we have not been able to locate a news article using the English "freedom of panorama" or the French "liberté de panorama" before 2011. Not that the topic was never mentioned. The emblematic case of the commercial use of Buren and Drevet artwork in Lyon has drawn the interest of 
leading French media 41 : the issue was framed in terms of a limitation of authors' rights rather than a positive user right.

This media treatment dramatically shifted since 2010. Prior to this year 42 results for the query "freedom of panorama" on Google are mostly Wikimedia-related (it prominently features discussions from Wikimedia Commons), whereas news articles make up for most of the results in the 2010-2016 period 43 .

Not only did the media "discover" freedom of panorama, but they devoted a much wider coverage to this issue than to any other exception contemplated in the EU copyright reform plans. In the English-speaking news, there is a strong surge of articles at each major peak of the EU debate. In June 2015, the possibility of a uniform non-commercial Freedom of panorama initiated significant controversies in countries that had already adopted a broader exception. The reception in the United Kingdom was especially hot in the wider context of the pre-Brexit campaign.

The mainly Wikimedian use of the expression "freedom of panorama" before the subsequent media interest raises an intriguing question: could the communities have partly set the news agenda? The earliest articles on the topic certainly points toward a direct influence. In September 2011, the leading French daily newspaper Le Monde published an op-ed of the president of Wikimedia France calling to "give their architectural landscape back to the French". In the subsequent few months, an amendment aiming at establishing a freedom of panorama was proposed (and rejected) by the French parliament.

Besides, Wikipedian communities were heavily involved during the most heated phase of the European legal debates from June to July 2015, before the vote of the Commission. No less than 19 chapters of Wikipedia displayed a banner in favour of 'Freedom of Panorama' that has been likely read by millions of Europeans.

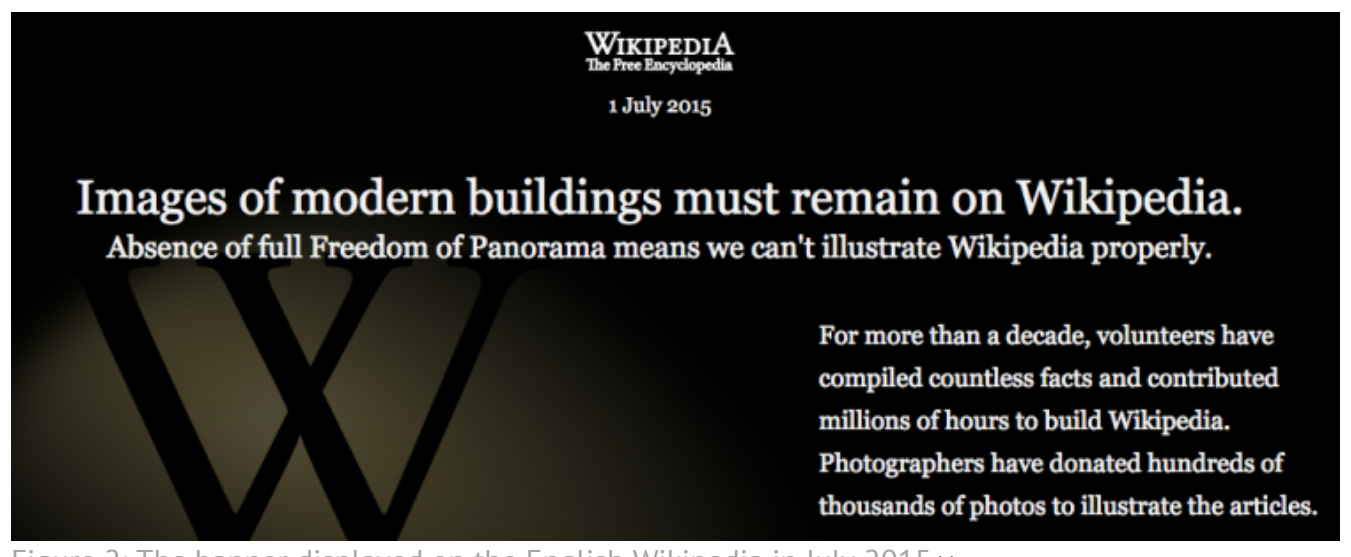

Figure 2: The banner displayed on the English Wikipedia in July 201544

\subsection{MODELING THE DISSEMINATION OF A COMMUNITY-SHAPED DISCOURSE IN THE FRENCH PRESS}

All in all, there has certainly been an influence, but has this been lasting enough to affect the way the media dealt with the issue? To track the process of dissemination of a communityshaped discourse within the public sphere we have used a combination of text mining techniques on both our French and English corpus.

The sub-discourses of the corpus were reconstructed by combining principal component analysis and an unsupervised classification technique (the "Reinert method") 45 on "segments" 
of texts (any arbitrary part of 40 consecutive words). With the reiterated co-occurrence of some words within each segment, wider semantic structure ("classes" or "topics") can be inferred, and linked to previous metadata (in this case, the name of the media).

The processing was made with Iramuteq (a text mining graphic application based on the $\mathrm{R}$ language) and the final output was visualised with an R library, ggplot. Analysis of the French corpus has yielded three classes that cover 616 segments of text (out of 780 : all the other segments could not be safely classified) into almost three equal parts (with 196, 193 and 227 segments). Not all classifications are significant, with $\mathrm{p}<0.05$ for $77-78 \%$ of the words in each class. The attribution of each media to a specific class yields comparable results (with $\mathrm{p}<0.05$ for four media out of 27). While the techniques we have used are far from perfect, theses uncertainties may also signal the degree of porosity and polysemy within specific parts of a discourse (that's especially true of the "media").

The two graphs below map the three main "clusters" of coherent genres in the French press.

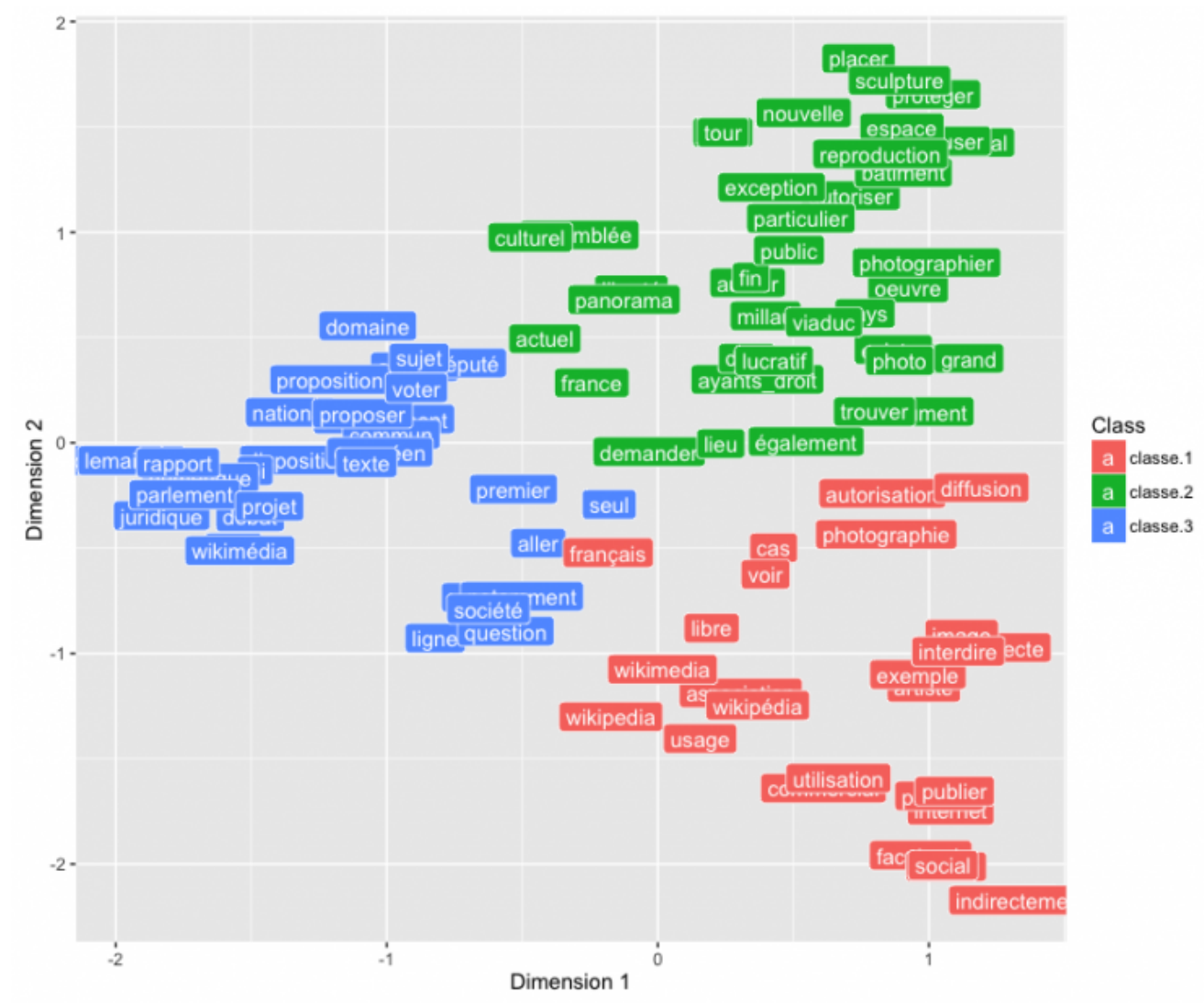

Figure 3: Words and media correspondence in the French corpus 


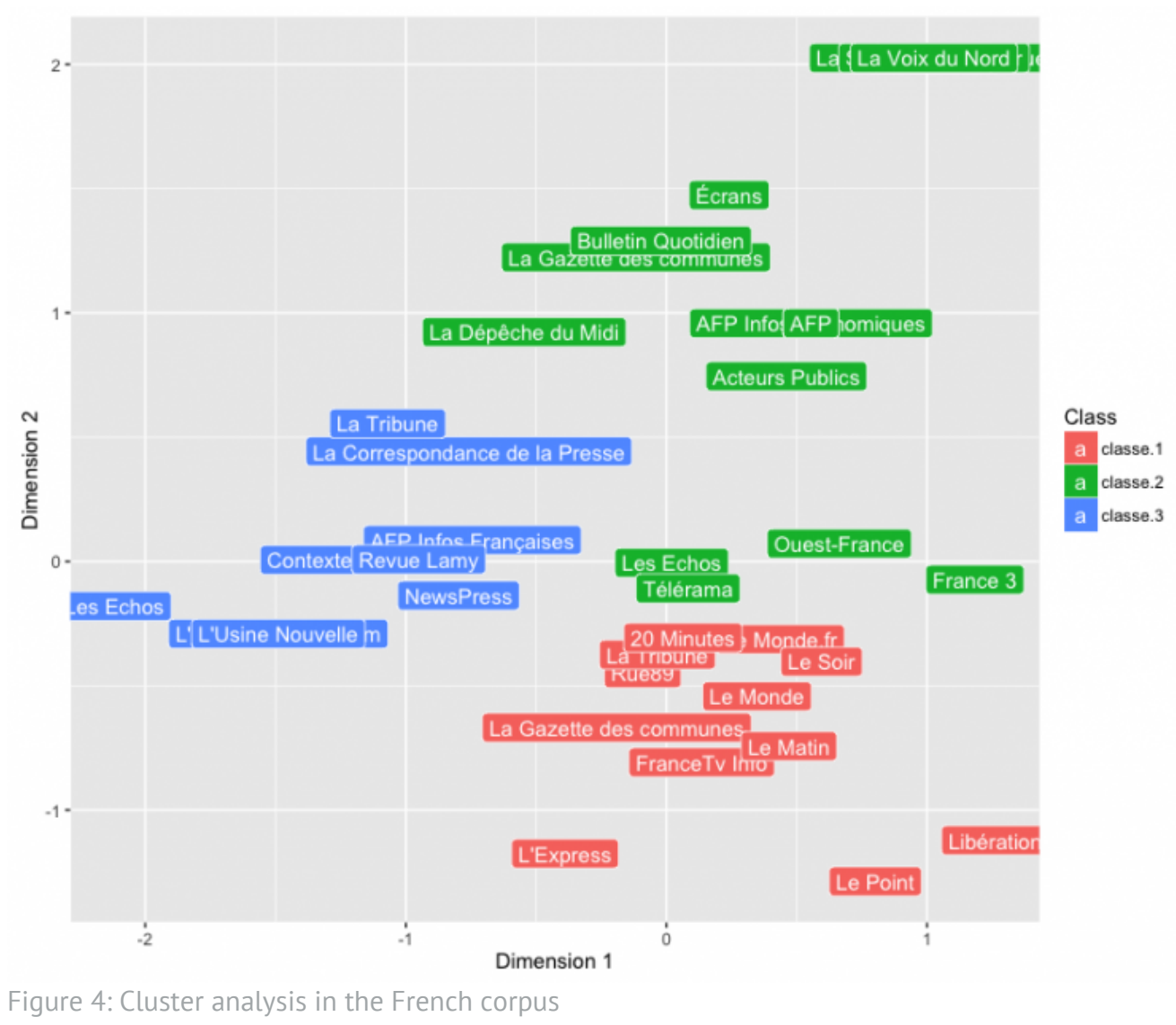

The closeness of each term and each media on the graph theoretically indicates their degree of affinity: terms which share a very close position would appear both very frequently in the same documents; in the same manner, media located on a similar coordinate will tend to use a similar array of terms. The blue and the green clusters mostly reflect inherent organisational news dynamics. Most of the "blue" media are specialised outlets that cover the evolution of law with a great deal of detail (such as Contexte, with $\mathrm{p}=0.002$ ). Conversely, "green" media are much more generalist and tend to extensively reuse news agency content. All the regional dailies are within this range and a closer look to the corpus reveals numerous identical wires taken from Agence France Presse (with $\mathrm{p}=0.01$ ).

The "red" cluster clearly escapes this easy classification. With the exception of regional newspapers, all the main "genres" of the current news landscape are covered, including national dailies (Le Monde, Libération), popular free daily (2o minutes), specialised outlet (La Gazette des communes). Within this cluster, media classification becomes actually fairly uncertain (for instance, $\mathrm{p}=0.14$ for Rue89).

A closer examination of the words classified in the cluster suggest that the lexical "coherence" identified by statistical methods may come from the influence of a common source: Wikipedia. They actually mirror some specific preoccupations of Wikimedian contributors: "Wikipedia", "Wikimedia", free licenses ("libre", "licence"), and the specific problems created by commercial use ("usage", "commercial") and contractual authorisation ("authorization", "diffusion") on an encyclopedia using primarily a license authorising commercial use.

To further test this hypothesis, we have added articles from Wikimédia France (and from the lobbying platform it ran in favour of freedom of panorama: Libertédepanorama.fr) to our corpus and again ran our classification process. Given they are directly produced by a 
Wikimedian association, these texts would be expected to feature prominently in an hypothetical "Wikimedian" cluster. Unsurprisingly, not only are they included in the red cluster, but the likelyness of the classification is very strong $(\mathrm{p}<0.0001)$.

A closer look at the corpus shows that the red "segments" frequently refer to the Wikipedian community. The graph below maps the sequence of the unities of context (the 40 consecutive words classified by Iramuteq) within seven significant articles as colored tiles: the largest the tiles, the more the article were "focused" on a specific class.

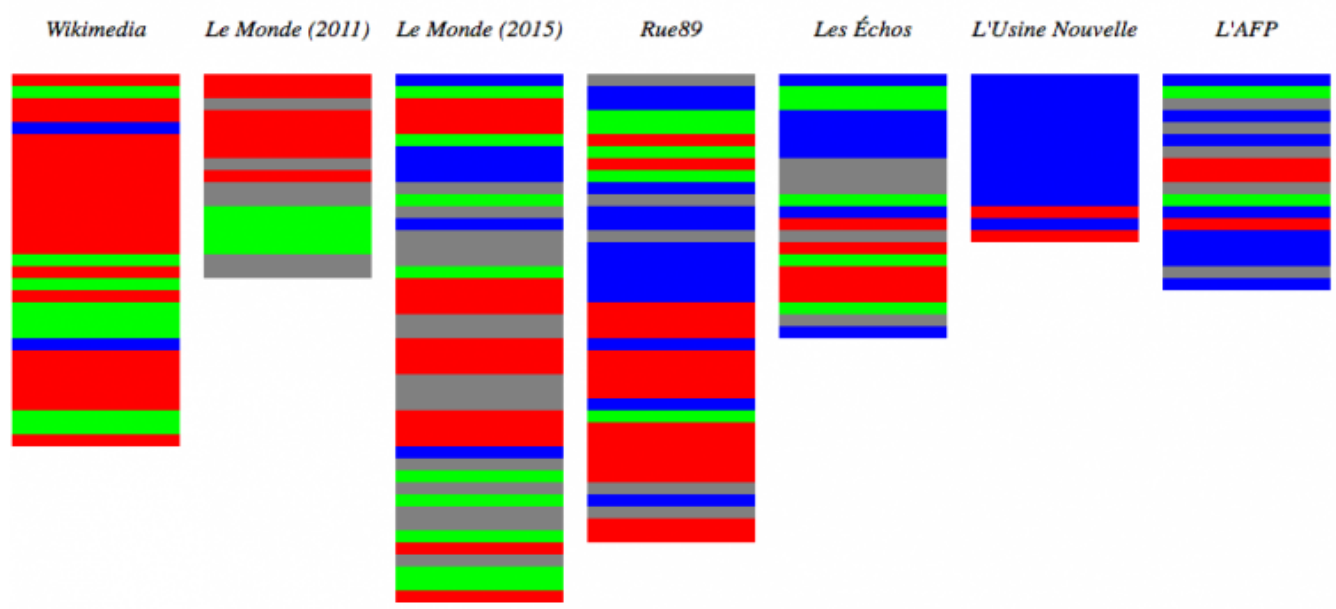

Figure 5: A closer look at the corpus

Unsurprisingly, the (aggregated) five small articles published by Wikimédia France on Libertédepanorama.fr in 2016 and the 2011 Wikimedian op-ed published on Le Monde easily stand out among the reddish pieces of our corpus. Generalist media extend the Wikimedian intricate discourse into more diversified texts. A Rue89 article of June 2015 combines both a "legal" section describing the technical issues of the law (mostly tagged in blue) with a focus on the feelings of Wikipedians who are said to be "quite worried" (mostly tagged in red) 46 . We find a similar construction in an article of the Le Monde published in May 2015: after exposing (in blue) the implications of the law, it echoed (in red) the reaction of the local Wikimedian association 47. On the other hand, specialist sources (such as L'Usine Nouvelle) are much more concerned with precise law implications (in blue).

The close and distant reading of the red cluster therefore points toward the influence of a community-shaped discourse on freedom of panorama within the media, that is sufficiently recognisable to overcome the varying writing habits of different news organisations.

\subsection{LOST IN THE NOISE? COMPETING DISCOURSES IN THE ENGLISH PRESS}

Our corpus of 53 English articles from Google News reveals a different picture. We used the same method as before: the Reinert method was applied to 1,040 segments of text (of which, 947 could be properly classified). While the number of class is higher ( 5 instead of 3 ), the Wikimedian-related words do not form an articulated cluster.

The clusters could refer to enunciation pattern: more generalist (on the left-side with iconic examples: the Eiffel Tower, the London Eye) vs more specific (on the right-side), and more neutral/detached (on the lower side with explicit references to the European Commission jargon) vs more engaged (on the upper side, either for or against freedom of panorama: The Register, which opposed Wikipedian views is very close to the petition launched on Medium). 


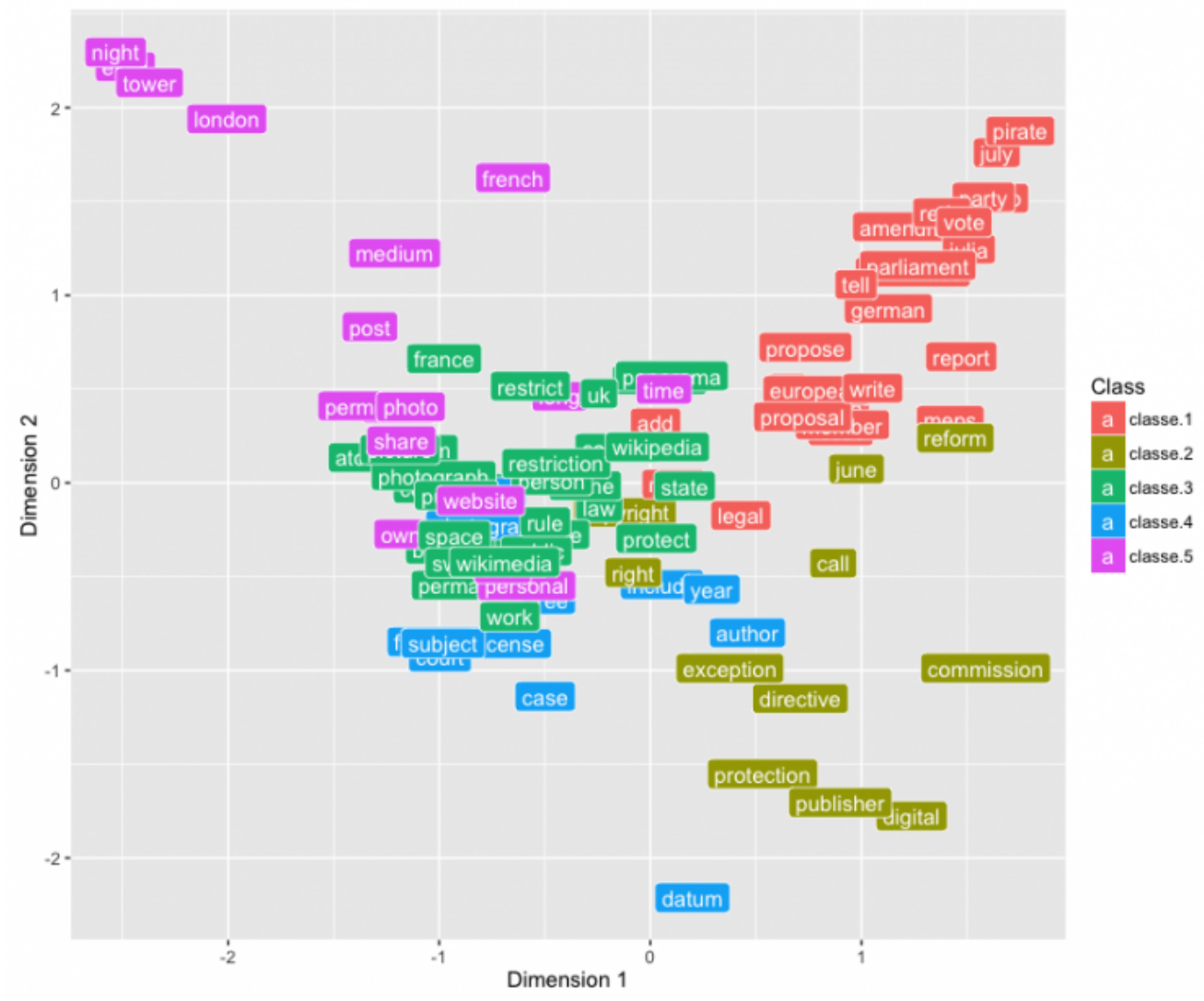

Figure 6: Words and media correspondence in the English corpus.

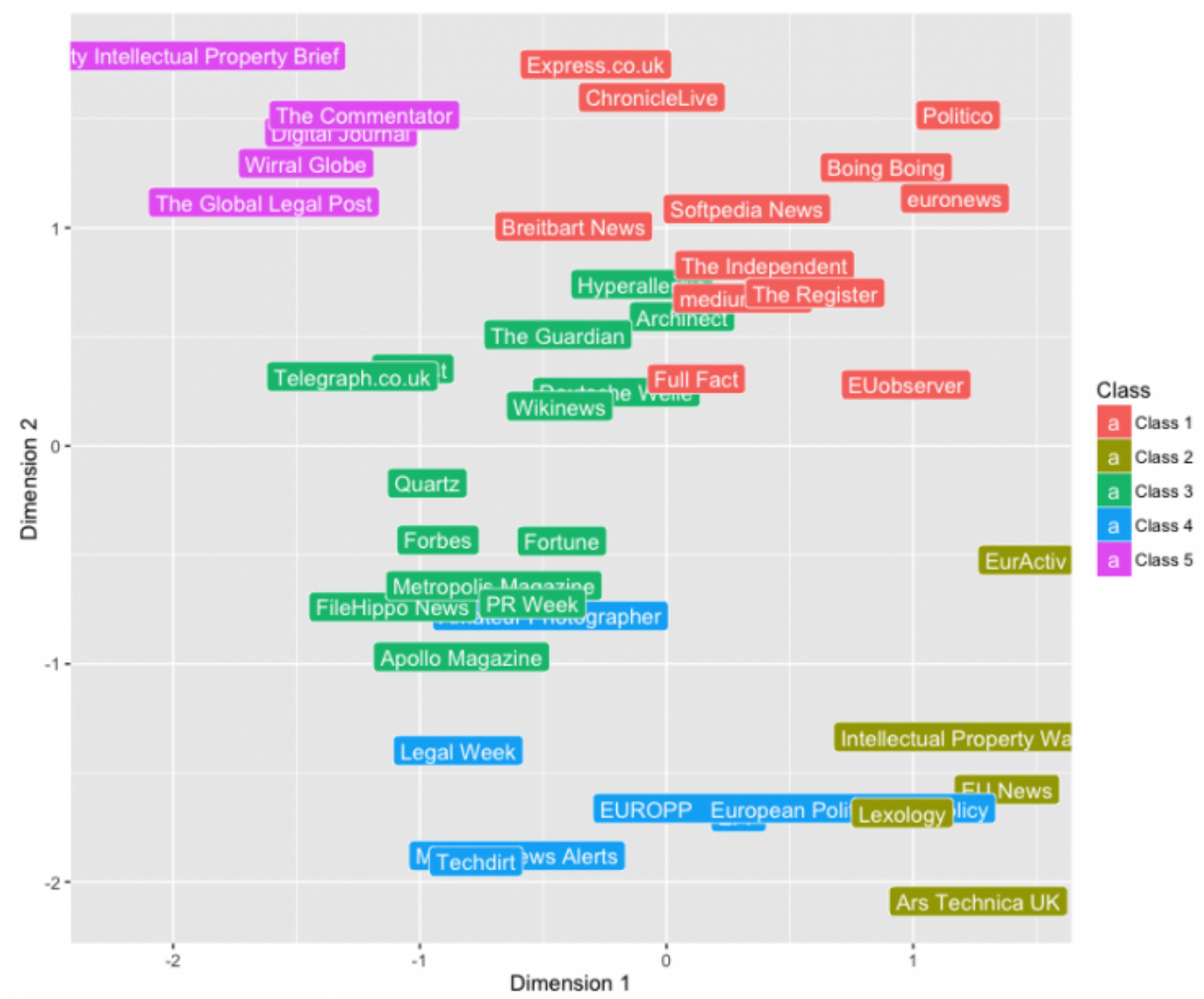

Figure 7: Cluster analysis in the English corpus

Nevertheless, as shown by the confusing "nucleus" in the correspondence analysis and the lower 
degree of significance (with p-value $<0.05$ for $69 \%$ to $74 \%$ of the words), classification remains much more shallow. While Wikimedians were an active part of the media debate (as satirised by The Register, they “jumped aboard the Freedom of panorama bandwagon 48 "), they weren't alone. Other competing groups also saw the controversy as an opportunity. For instance farright news site Breitbart and members of parliament of the UKIP party ${ }_{49}$ reframed the debate as a chauvinistic defense against European normalisation.

While freedom of panorama is clearly a global issue and transnational communities (such as Wikipedia) contribute to the circulation of concepts beyond national boundaries, the news coverage remains shaped by specific legal situations within the EU and, consequently, by conflicting strategies. Given the fact that they were pushing forward a new law rather than defending an existing one, our hypothesis is that French Wikimedians conveyed a more structured and vocal discourse to the media. This strong involvement did not really yield the expected results: at most, it may have helped to secure a very limited non-commercial exception, while being unable to prevent the extension of the law to public domain buildings and to wholly change the French policy agenda in Brussels. The gap between the mostly pro-Freedom of panorama stance in the media and the outcomes of the legal debate could hardly be wider.

The dissemination of "freedom of panorama" in the media may also be analysed in terms of a long-term investment, that goes beyond a specific legal debate. As we have seen in the first section, the legal treatment of panorama has long been a complex construct involving different cultural norms and legal principles. Establishing "freedom of panorama" as a regular news topic may, in itself, be understood as a significant change in social attitudes towards copyright.

\section{CONCLUSION}

In this article, we presented the origins of the copyright exception to reproduce public artworks, the legal framework of freedom of panorama, the arguments developed by lobbyists on both sides and the disproportionate role taken by the Wikimedia community in the agenda-setting and the mediatic sphere. We demonstrated that beyond legal and policy arguments, the controversy is revolving around the notion of commercial use, which is neither defined, nor measured.

Several policy options are available and will be arbitrated by lawmakers. As the copyright directive revision proposal does not include it as a new exception, it is unlikely that a future provision will harmonise the exception of panorama as requested by the public domain advocates, unless the EU parliament takes a strong stance in favour of minimal harmonisation (as suggested by the latest report of the Committee of Culture and Education). Now that France and Belgium have set a trend of settling the issue in two conflicting directions, other member states may also go down singular routes. This will come in due course, when they will want to update their copyright law and when transposing the forthcoming European Directive. They may follow the route of rightholders lobbyists and maintain current practices of collective collection in the countries where they exist. Alternatively, intermediary measures could be implemented. The freedom of panorama could be granted for non-commercial uses only, or become a limitation with a levy. Both options would reduce the scope of users' rights in countries which already have a broad exception. Finally, a solution to be explored to compensate artists in countries which have exclusive rights would be to develop national subsidy. Such a solution of compromise has been adopted in France to develop an open access policy in the field of scientific publications, while subsidising the local social science publishing industry. 
Another more straightforward solution to avoid the never-ending conflict on the nature of downstream commercial uses allowed by the Wikipedia license could be, as suggested twice in the paper as compatible with recent French and European texts, to recognise the role of the encyclopedia as a memory institution, as a public service actor which would benefit from an exception, which would not be transmitted to potential commercial re-users along the Creative Commons license.

\section{ACKNOWLEDGEMENTS}

They are grateful for discussions with Thierry Maillard and Marie-Anne Ferry-Fall (ADAGP, Association pour la diffusion des arts graphiques et plastiques, French royalty collecting and distribution society in the field of graphic and visual arts), Anne-Catherine Lorrain (Policy Advisor on Legal Affairs, Greens/EFA Group, European Parliament) and Dimitar Dimitrov (Wikimedia Europe).

They are also grateful for useful comments after a presentation of a previous version at the LSE Law and Communications research network and at the CPT meeting of the IAMCR conference in Leicester. 


\section{REFERENCES}

Angelopoulos, C. (2012). The myth of European term harmonisation: 27 public domains for the 27 member states. International Review of Intellectual Property and Competition Law, 43(5), 567-594. http://dx.doi.org/10.2139/ssrn.2145862

Ambühl, F., Beutler, S. (2011). Fotografieren verboten! - Zum Spannungsverhältnis von Urheber- und Eigentumsrecht im Fotografiebereich. Recht, 2011(1), 14-19.

Bullich, V. (2011). Le droit d'auteur en regard de la théorie des industries culturelles. Les Enjeux de l'information et de la communication, 12(1), 51-67.

Bertoni, A., Montagnani, M. L. (2015). Public architectural art and its spirits of instability. Queen Mary Journal of Intellectual Property, 5(3), 247-263.

http://doi.org/10.4337/qmjip.2015.03.01

Bently, L. \& Kretschmer, M. (Eds). Directive for reciprocal copyright protection within the German Confederation, Berlin (1837), Primary Sources on Copyright (1450-1900), www.copyrighthistory.org

Cammaerts, B., Mansell, R., Meng, B. (2013). Copyright \& Creation A Case for Promoting Inclusive Online Sharing. Media Policy Project 9: 1-18. The London School of Economics and Political Science.*

http://www.lse.ac.uk/media@lse/documents/MPP/LSE-MPP-Policy-Brief-9-Copyright-and-Cr eation.pdf

Chirco, C. G. (2013). Die Panoramafreiheit: Die Beschränkung des urheberrechtlichen Schutzes von Kunst im öffentlichen Raum. Baden-Baden: Nomos.

Cooper, E. (2016), How art was different: Researching the history of artistic copyright. In I. Alexander \& H.T. Góez-Arostegui (Eds.), Research Handbook on the History of Copyright Law (158-176). London: Edward Elgar.

Dessemontet, F. (1999). Le droit d'auteur. Centre du droit de l'entreprise de l'Université de Lausanne.

Dusollier, S., Benabou, V.-L. (2007). Draw me a public domain in Torremans, P. (ed.), Copyright Law: A Handbook of Contemporary Research, Edward Elgar.

http://works.bepress.com/severine_dusollier/5/

Dusollier, S. (2011). Scoping Study on Copyright and Related Rights and the Public Domain. WIPO Publication CDIP/7/INF/2.

http://www.wipo.int/meetings/fr/doc_details.jsp?doc_id=161162

Geissler, R. (2016). Private Eyes Watching You: Google Street View and the Right to an Inviolate Personality, Hastings Law Journal, 63(1), 897-926.

http://dev.hastingslawjournal.org/wp-content/uploads/Geissler-63.3.pdf

Gibbs-Smith, C. (1970), Copyright Law Concerning Works of Art, Photographs and the Written Word. London: Museum Association. http://files.eric.ed.gov/fulltext/EDo53746.pdf

Newell, B. C. (2011). Freedom of Panorama: A Comparative Look at International Restrictions on Public Photography. Creighton Law Review, ${ }^{*}$ 2010-2011*(44), 405-426. Available at 


\section{SSRN:http://ssrn.com/abstract $=1709530$}

Lobert, J., Isaias, B., Bernardi, K., Mazziotti, G., Alemanno, A., \& Khadar, L. (2015). The EU Public Interest Clinic and Wikimedia Present: Extending Freedom of Panorama in Europe. HEC Paris Research Paper No. LAW-2015-1092. http://doi.org/10.2139/ssrn.2602683

Lorrain, A.-C., \& Reda, J. (2015). Freedom of Panorama: A Political "Selfie" in Brussels. European Intellectual Property Review, 37(12), 753-755.

Manara, C. (2016). La Nouvelle « Exception De Panorama ». Gros Plan Sur L'Article L. 122-5 $10^{\circ} \mathrm{Du}$ Code Français De La Propriété Intellectuelle (The New 'Panorama Exception' in French Copyright Law), Revue Lamy Droit de l'Immatériel, août-septembre 2016, n 4049, pp. 40-43. Available at SSRN: https://ssrn.com/abstract $=\mathbf{2 8 2 8 3 5 5}$

Mazzone, J. (2011). Copyfraud and other abuses of intellectual property law. Stanford, California: Stanford Law Books, Stanford University Press.

Murray, A. (2007). The Regulation of Cyberspace. Routledge.

Nobre, T. (2016). Freedom of Panorama in Portugal. Communia Best Case Scenario for Copyright.

http://www.communia-association.org/wp-content/uploads/2016/o6/BCS_Communia_FoP_s tudy.pdf

Morando, F. (2011), Diritti sui beni culturali e licenze libere, https://ssrn.com/abstract=2148343

Popova, P. (2012). Copyright law: impacts on urban shaping, Fourth annual Workshop of the International Society for the History and Theory of Intellectual Property (ISHTIP).

Rehbinder, M. (1993). Schweizerisches Urheberrecht. Stämpfli.

Marpsa, M. (2010). La Méthode Alceste. Sociologie, 1(1). https://sociologie.revues.org/312

Ridley, R. T. (1992), The Eagle and the Spade: Archaeology in Rome During the Napoleonic Era, Cambridge University Press.

Schricker, G., \& Dreier, T. (1997). Urheberrecht auf dem Weg zur Informationsgesellschaft. Nomos.

Tissot, T. (2001), La Photographie et l'appropriation de la rue : quelle morale ? (1850-1900). In Parcourir et gérer la rue parisienne à l'époque contemporaine: pouvoirs, pratiques et représentations. Paris: L'Harmattan.

\section{FOOTNOTES}

1. This reproduction was featured on the corresponding article on the French Wikipedia until the recent introduction of freedom of panorama in Belgium in July 2016. Source:

https://commons.wikimedia.org/wiki/File:Atomium_o10-censored.png (CCo)

2. The methodology for the literature review relied on a systematic search for the keywords "freedom of panorama" and "public art" in databases (CNRS INIST, LSE and Google Scholar) 
3.

http://www.politico.eu/article/banned-taking-pictures-of-the-eiffel-tower-at-night-copyright-la $\mathrm{w}-\mathrm{eu} /$

4. In Ngram Viewer, a tool which allow to measure the occurrences of word in an extensive selection of google books, the expression "Panoramafreiheit" is simply not attested.

5. On this major challenge to pre-existing copyright law, see Cooper, 2016 and Murray, 2007, p. 15.

6. For instance, one of the few identified examples were linked to the diffusion of a postcard of a sculpture in the early 1920 s https://jastrow.wordpress.com/2011/10/25/panorama-sansceremonies/

7. On this little known piece of legislation, see Ridley, 1992, p. 16. This was an extension of preexistent law restraining the use and export of "antiquities". This whole body of law has never been well applied: "the endless repetition of the same repetition of the same general restriction shows their utter ineffectiveness" (ibid).

8. Directive for reciprocal copyright protection within the German Confederation, Berlin, art. 1.

(L. Bently \& M. Kretschmer).

9. See the presentation of the law in Primary Sources on Copyright :

http://www.copyrighthistory.org/cam/tools/request/showRecord.php?id=record_d_1837b

10. $\S 59$ (English translation) of the Urheberrechtsgesetz, the Act on Copyright and Neighboring Rights, and a case of the Federal Court of Justice, BGH, I ZR 192/oo = GRUR 2003, 1035 Hundertwasserhaus excluding a photograph taken from a private balcony.

11. One of the earliest occurrences appeared in Rehbinder (1993).

12. The French "liberté de panorama" appears before the English "freedom of panorama" in another Swiss manual of jurisprudence (Dessemontet, 1999).

13. See for instance the occurrence of the word within a 1997 legal focus on information society: Schricker and Dreier, 1997, p. 171.

14. Cour de Cassation, Chambre civile 1, du 15 mars 2005, 03-14.820. Analysis in English.

15. These explanations are based on the Wikipedia page description of applicable rights: https://commons.wikimedia.org/wiki/Commons:Freedom_of_panorama

16. Directive 2001/29/EC of the European Parliament and of the Council of 22 May 2001 on the harmonisation of certain aspects of copyright and related rights in the information society, Official Journal L 167, 22/06/2001 P. 0010 - 0019.

17. Section 62 of the UK Copyright, Designs and Patents Act 1988.

18. Quoted from an article in Politico:

http://www.politico.eu/article/banned-taking-pictures-of-the-eiffel-tower-at-night-copyright-la w-eu/

19. Belgium. Loi modifiant le Code de droit économique en vue de l'introduction de la liberté de 
panorama, adoptée le 27 Juin 2016 et entrée en vigueur le 15 juillet 2016 . Translation by the author.

20. France. Loi $n^{\circ}$ 2016-1321 du 7 octobre 2016 pour une République numérique, JORF nº235 du 8 octobre 2016. https://www.legifrance.gouv.fr/eli/loi/2016/10/7/ECFI152425oL/jo/texte. Translation by the author.

21.

http://the1709blog.blogspot.co.uk/2016/10/the-new-but-narrow-french-freedom-of.html?m=1

22. France. Projet de loi relatif à la liberté de la création, à l'architecture et au patrimoine Version définitive, 29 juin 2016. Translation by the author.

23. France. Loi nº2016-925 du 7 juillet 2016 - art. 75. Translation by the author.

24. Interview with stakeholders on both sides.

25. The French castle of Chambord could not prevent a beer trademark to use its image in an advertising campaign. Litigation is currently in front of the supreme court (Conseil d'Etat) after CAA Nantes, Formation plénière, 16/12/2015, 12NTo1190. See more, including the litigious ad, here and here.

26. Interview by the authors.

27. Therefore effectively destroying other collecting societies' claim not to sue individuals.

28. Translation by the author. Original source here:

http://tinlot.blogs.sudinfo.be/archive/2016/o7/17/photographier-dans-un-lieu-public-en-belgi que-une-loi-consac-195229.html

29. Nevertheless on the French side, the invocation of "cultural exception" ("exception culturelle") remains a strong argument against a wider European copyright reform. In that sense, listen to the response of French senators.

30. Discussions between the author and collecting societies since 2003.

31. See figures here:

http://www.adagp.fr/fr/actualites/tout-ce-que-vous-avez-toujours-voulu-savoir-sur-l-exception -panorama

32. Private communication.

33. See figures here:

http://www.ace-cae.eu/fileadmin/user_upload/Publications/EN_Country_Prof_Sector_Study _2012.pdf

34. Committee report on the implementation of Directive 2001/29/EC of the European Parliament and of the Council of 22 May 2001 on the harmonisation of certain aspects of copyright and related rights in the information society Committee on Legal Affairs.

35. Save the Freedom of Photography! \#saveFoP, change.org, 2015. As noted by rightholders, the petition proponent manages a business of litigation for photographies commercial use infringement. 
36. European Parliament resolution of 9 July 2015 on the implementation of Directive 2001/29/EC of the European Parliament and of the Council of 22 May 2001 on the harmonisation of certain aspects of copyright and related rights in the information society (2014/2256(INI)).

37. Proposal for a DIRECTIVE OF THE EUROPEAN PARLIAMENT AND OF THE COUNCIL on copyright in the Digital Single Market, COM(2016) 593 final, 2016/0280(COD)

http://eur-lex.europa.eu/legal-content/EN/TXT/HTML/?uri=CELEX:52016PCo593\&from=EN

38. Access report here:

http://www.europarl.europa.eu/sides/getDoc.do?pubRef=-\%2f\%2fEP\%2f\%2fNONSGML\%2bC OMPARL\%2bPE-595.591\%2bo1\%2bDOC\%2bPDF\%2bVo\%2f\%2fEN

39. This selection choice brings a lot of methodological issues and caveats. For a detailed account, see our supplementary data paper on Github

40. The closest thing that comes to it is an article from the Register criticising the Wikimedian campaign.

41. Cf. the article of Le Monde in 2005:

http://www.lemonde.fr/culture/article/2005/03/17/la-cour-de-cassation-limite-le-droit-d-aute ur-de-daniel-buren-et-christian-drevet_401955_3246.html?xtmc=daniel_buren\&xtcr=36

42. See query results here:

https://www.google.fr/search?q=\%22freedom+of + panorama\%22\&client=firefox-b\&biw=1377\& bih=721\&source=lnt\&tbs=cdr\%3A1\%2Ccd_min\%3A01\%2Fo1\%2F1995\%2Ccd_max\%3Ao1\%2Fo 1\%2F2010\&tbm=

43. See query results here:

https://www.google.fr/search?q=\%22freedom+of+panorama\%22\&client=firefox-b\&biw=1377\& $\mathrm{bih}=721 \&$ source $=\operatorname{lnt} \& t \mathrm{bs}=\mathrm{cdr} \% 3 \mathrm{~A} 1 \% 2 \mathrm{Ccd} \_\mathrm{min} \% 3 \mathrm{A01} \% 2 \mathrm{Fo1} \% 2 \mathrm{~F} 2 \mathrm{O} 10 \% 2 \mathrm{Ccd} \_\mathrm{max} \% 3 \mathrm{A01} \% 2 \mathrm{~F}$ $01 \% 2 \mathrm{~F} 2016 \& \mathrm{tbm}=$

44. Figure 3 was drawn from:

https://meta.wikimedia.org/wiki/Freedom_of_Panorama_in_Europe_in_2015

45. For a comprehensive summary of the Reinert method, see Marpsat, 2010.

46. Article by Rue89:

http://rue89.nouvelobs.com/2015/o6/30/photo-liberte-panorama-a-peine-evoquee-france-dej a-menacee-260028

47. Article by Le Monde:

http://www.lemonde.fr/arts/article/2015/05/o8/liberte-de-panorama-ce-que-peut-changer-ce tte-exception-au-droit-d-auteur-pour-l-architecture-ou-le-street-art_4629904_1655012.html

48. Article in The Register:

http://www.theregister.co.uk/2015/o7/02/wikipedia_jumps_on_bogus_photo_scare_to_tell_ us_the_internet_is_breaking_again/

49. Article in Express:

http://www.express.co.uk/news/uk/586262/European-Union-ban-photos-freedom-of-panora 
ma-Angel-of-North-London-Eye 